\title{
EXPERIMENTAL
} NEUROSCIENCES

\section{Incomplete Assessment of Experimental Cytoprotectants in Rodent Ischemia Studies}

\author{
Suzanne B. DeBow, Darren L. Clark, Crystal L. MacLellan, Frederick Colbourne
}

\begin{abstract}
Background: Inadequate preclinical testing (e.g., rodent studies) has been partly blamed for the failure of many cytoprotectants to effectively treat stroke in humans. For example, some drugs went to clinical trial without rigorous functional and histological assessment over long survival times. In this study, we characterized recent experimental practices in rodent cytoprotection experiments to determine whether the limitations of early studies have been rectified. Methods: We identified 138 rodent cytoprotection studies published in several leading journals (Journal of Neuroscience, Stroke, Journal of Cerebral Blood Flow and Metabolism and Experimental Neurology) for 2000 - 2002 and compared these to those published in 1990. From each study we determined the ischemia model, age and sex of the animal, the histological and functional endpoints used, and the methodology used to assess intra- and postischemic temperature. Results: Ninety-eight percent of recent studies used young adult rodents and most used males. Most studies $(60 \%)$ did not assess functional outcome and survival times were often $\leq 48 \mathrm{hr}(66 \%)$ for focal ischemia and $\leq 7$ days $(80 \%)$ for global ischemia. Over $60 \%$ of the experiments relied solely upon rectal temperature during ischemia and only $32.6 \%$ of ischemia studies measured temperature after surgery. The 1990 data were similar. Conclusions: Many investigators ignore the need to assess long-term functional and histological outcome and do not accurately represent clinical conditions of ischemia (e.g., use of aged animals). In addition, intra- and postischemic temperature measurement and control is frequently neglected or inadequately performed. Further clinical failures are likely.
\end{abstract}

RÉSUMÉ: Évaluation incomplète des cytoprotecteurs expérimentaux dans les études sur l'ischémie chez les rongeurs. Introduction: Une évaluation préclinique inadéquate (i.e. études chez les rongeurs) semble en partie responsable de l'inefficacité de plusieurs cytoprotecteurs pour traiter l'accident vasculaire cérébral chez l'humain. À titre d'exemple, certains médicaments ont atteint la phase des essais thérapeutiques sans évaluation fonctionnelle et histologique rigoureuse à long terme. Dans cette étude, nous décrivons les pratiques expérimentales actuelles au cours d'évaluations de cytoprotection chez les rongeurs pour déterminer si les lacunes des études antérieures ont été corrigées. Méthodes: Nous avons identifié 138 études de cytoprotection chez des rongeurs publiées dans plusieurs journaux prestigieux (Journal of Neuroscience, Stroke, Journal of Cerebral Blood Flow and Metabolism et Experimental Neurology) de 2000 à 2002 et nous les avons comparées à celles publiées en 1990. Pour chaque étude, nous avons examiné le modèle d'ischémie, l'âge et le sexe des animaux, les critères d'évaluation histologiques et fonctionnels et la méthodologie utilisée pour évaluer la température intra et postischémie. Résultats: Quatre-vingt-dix pour cent des études portaient sur de jeunes rongeurs adultes et la plupart étaient des mâles. La plupart des études (60\%) n'évaluaient pas l'issue fonctionnelle et le temps de survie était souvent de $£ 48$ heures (66\%) pour l'ischémie focale et de $£ 7$ jours $(80 \%)$ pour l'ischémie globale. Plus de $60 \%$ des études étaient basées uniquement sur la température rectale pendant l'ischémie et seulement 32.6\% des études mesuraient la température après la chirurgie. Les données de 1990 étaient semblables. Conclusions: Plusieurs chercheurs ignorent l'importance d'évaluer les résultats fonctionnels et histologiques à long terme et ne reproduisent pas avec exactitude les conditions cliniques de l'ischémie (i.e., utilisation d'animaux âgés). De plus, la mesure et le contrôle de la température intra et postischémie sont souvent négligés ou faits de façon inadéquate. D’autres échecs cliniques sont à prévoir.

Can. J. Neurol. Sci. 2003; 30: 368-374

Animal research has and will undoubtedly continue to improve outcome for humans who suffer from cerebral ischemia (e.g., stroke). However, the hope for an effective cytoprotective (cell saving) drug has given way to pessimism as these compounds have repeatedly failed clinical scrutiny. ${ }^{1}$ A number of likely explanations have been proposed. ${ }^{1-4}$ For instance, in many clinical trials the putative cytoprotectant was given after an unrealistically long intervention delay. At such long delays those compounds also failed preclinical testing (i.e., rodent studies). Thus, clinical trials were not always accurately based upon preclinical studies.
Inadequate preclinical assessment is also partly to blame for the premature advancement of some therapies to the clinic. ${ }^{1-4}$ For instance, the stroke therapy academic industry roundtable $(\mathrm{STAIR})^{3}$ report recommended that putative cytoprotectants be

From the Department of Psychology and Center for Neuroscience, University of Alberta, Edmonton, Alberta, Canada.

ReCeived February 4, 2003. ACCePtedin Finalform June 11, 2003

Reprint requests to: Frederick Colbourne, Department of Psychology, P217 Biological Sciences, University of Alberta, Edmonton, AB, Canada T6G 2E9. 
tested in larger gyrencephalic species prior to clinical trials. However, efficacy has been and is based largely upon rodent ischemia models. One major limitation of many early studies has been the failure to assess long-term histological and functional outcome. Many studies in the 1980s and 1990s used survival times of one to two days for focal ischemia and four to seven days for global ischemia, which are sufficient to allow the majority of cell death to occur after moderate to severe ischemic insults. ${ }^{5-8}$ However, substantial cell death may evolve beyond these survival times when the insult is mild ${ }^{8-10}$ or treated with a cytoprotectant. ${ }^{11-14}$ For example, Dietrich et $\mathrm{al}^{11}$ showed that three hours of postischemic hypothermia reduced CA1 cell death at three and seven days following global ischemia, but did not save CA1 neurons at two months.

In addition to using survival times that did not allow for injury to completely mature, many early studies either did not assess functional outcome or used simplistic neurological deficit scores and only in the first few days after stroke. Remarkably, long-term functional outcome is the clinical endpoint of greater concern, and yet most experimental studies relied upon quantification of early cell death, which does not necessarily correlate with eventual behavioural outcome. ${ }^{2,15}$ Unfortunately, when behaviour was assessed, it was often done with a neurological deficit score (NDS) that not only varied among laboratories but was not able to precisely gauge longer-term deficits $^{16}$ or distinguish true preservation of function from compensatory processes. ${ }^{17}$

Stroke is more common in the elderly and yet the majority of early studies utilized young adult animals. Since there are outcome differences between young and old animals ${ }^{18-20}$ it seems appropriate to assess cytoprotectants in aged animals at some point. Furthermore, there are sex differences in ischemic injury and recovery ${ }^{21}$ and yet this is ignored in most studies.

Finally, early rodent studies were plagued by temperature confounds. Ischemia and the use of an anesthetic (e.g., halothane, sodium pentobarbital) induce hypothermia, which is the best cytoprotectant. Some early studies failed to measure temperature during ischemia yet, aside from blood flow, temperature is arguably the most critical determinant of ischemic injury. $^{22,23}$ Furthermore, studies that assessed intra-ischemic temperature often relied upon rectal temperature measurements, which do not necessarily correlate well with brain temperature. ${ }^{24-26}$ Accordingly, a drug may augment brain hypothermia even with core temperature maintained at normothermia. More recently, the importance of postischemic temperature has been recognized. Delayed fever substantially worsens global $^{27,28}$ and focal $^{29-32}$ ischemic damage, whereas delayed cooling reduces ischemic injury after global ${ }^{12,33,34}$ and focal cerebral ischemia. ${ }^{35-37}$ For example, hypothermia delayed for 12 hours after global ischemia significantly reduced CA1 neuronal loss. ${ }^{38,39}$ The consequence of not carefully assessing intra- and postischemic temperature is best illustrated by the findings with MK- $801^{40,41}$ and $\mathrm{NBQX}^{42}$ that reduced CA1 cell death largely or completely by inducing hypothermia.

The aforementioned limitations of experimental stroke studies have also been identified in literature reviews. ${ }^{1-4}$ In this study we surveyed all of the publications in Experimental Neurology, Journal of Cerebral Blood Flow and Metabolism, the Journal of Neuroscience and Stroke for the years of 2000, 2001 and 2002 combined, and this was compared to studies published in 1990 in the same journals. We identified those ischemia studies that used adult to aged rodents to assess the efficacy of a cytoprotective treatment on histological and/or functional outcome. The purpose of this survey was to characterize recent ischemia studies and more importantly to determine whether these studies are plagued by methodological limitations.

\section{MATERIALS AND METHODS}

\section{Survey scope}

We identified all of the rodent ischemia articles published in the Journal of Neuroscience, the Journal of Cerebral Blood Flow and Metabolism, Experimental Neurology and Stroke for the years of 2000, 2001 and 2002 combined along with the year of 1990. Data were collapsed across the years 2000 to 2002 to improve the sample size of recent studies, which is the primary focus of this survey, and because we did not observe any notable change in practices during this time. In rare cases, two models and/or species were used in one publication. These were then considered to be separate studies. Only studies that used adult to aged rodents to assess global or focal ischemic insults were included; all others were excluded (e.g., neonatal hypoxia). We limited the survey to rodent models since these are, by far, the most commonly used to determine efficacy and mechanisms of action. Of these adult ischemia studies we included only those that tested a putative "cytoprotective" therapy (e.g., glutamate antagonist). A cytoprotection study was defined as one in which a therapy was administered (most common) or a genetic manipulation was made (e.g., knockout mouse; only a few studies) and the effects of that therapy were assessed on histological (including MRI determined lesion volumes) and/or behavioural outcome. Studies that only examined intra- and/or postischemic cellular alterations (e.g., caspase activation), without direct manipulation, were not included. Studies that examined very late interventions (e.g., stem cell transplants one week after stroke) were not included.

A survey approach of four journals was chosen over a computerized literature search for several reasons including: 1) to limit the number of articles, 2) to ensure that each article included in the survey conformed to the above criteria, which required a detailed examination of each article, and 3) to avoid missing articles that did not use cytoprotection, neuroprotection or drug therapy, etc. as a subject heading, but were nonetheless efficacy studies.

\section{Identification of rodent models}

Studies surveyed used either rats, mice or gerbils. Global ischemia models in the rat included the two-vessel occlusion plus systemic hypotension and four-vessel occlusion models. In the gerbil and mouse the forebrain ischemia model used was bilateral common carotid artery occlusion. Focal ischemia studies used middle cerebral artery occlusion models either by intraluminal suture occlusion, clot occlusion (i.e., embolic model, photo thrombosis), electrocauterization or clip occlusion (or like procedure) of the middle cerebral artery.

\section{Identification of species, sex and age}

The species, sex and age of animals were identified. Many 
studies did not state the animals'age but instead stated a weight range. In these cases, we categorized the age as undetermined since weight is not a reliable predictor of age and is also influenced by sex, health status, strain, etc. We assumed that these studies used young adults.

\section{Identification of temperature measurement technique}

The methods used to measure intra- and postsurgery temperature were identified and categorized into: 1) rectal or core, 2) temporalis muscle or tympanic with or without measuring rectal/core temperature, and 3) brain temperature with or without other measurement methods. Postsurgery temperature measurement was defined as any measurement beyond the end of surgery and this was divided into the times of $0-2 \mathrm{hr}, 2-6 \mathrm{hr}, 6$ - $12 \mathrm{hr}$ and $12-24 \mathrm{hr}$ (i.e., > 12 but $\leq 24 \mathrm{hr}$ ) after surgery. The sampling rate was categorized as: 1 ) continual (sampling at least every 15 minutes or continuously), 2) frequent (sampling every 16 - 60 minutes), 3) infrequent (sampling every 61 - 120 minutes), 4 ) rarely ( $<1$ sample every $2 \mathrm{hr}$ ) or 5 ) no postoperative sampling.

\section{Survival time and choice of endpoint}

The survival time (hours to days following the start of ischemia) was categorized (e.g., 0 - $24 \mathrm{hr}, 25-48 \mathrm{hr}$, etc.) for both global and focal ischemia studies. Behavioural evaluation was categorized as: absent, a NDS (e.g., a scale that includes ratings of spontaneous circling and activity, paw placement, etc.) or additional testing (e.g., skilled reaching, water maze testing, rotarod) with or without the NDS. Those studies that only used a behavioural evaluation procedure to determine whether animals were ischemic or not, but did not assess whether a treatment affected behavioural outcome, were not considered to have used behavioural assessments as an efficacy endpoint.

\section{RESULTS}

According to our criteria of an efficacy study, we identified 19 and 20 global ischemia experiments for 1990 and 2000 2002, respectively. There were six and 118 focal ischemia experiments for 1990 and 2000 - 2002, respectively. The types of model, sex and age characteristics are reported in the Table. The vast majority of studies used male rodents and only two recent studies used old animals (> one year old). The intraluminal suture occlusion model has clearly replaced electrocautery as the preferred model of focal ischemia. Interestingly, almost all studies report positive results.

Survival time varied greatly for both focal and global ischemia studies (Figure 1). Eighty percent of recent global ischemia experiments used survival times of $\leq$ seven days. Sixtysix percent of recent focal ischemia studies used survival times of $\leq 48 \mathrm{hr}$ whereas only $8.5 \%$ of focal ischemia studies examined histological outcome after seven days. These results mirror those in 1990.

Out of 20 recent global ischemia studies only two assessed behaviour, which compares well to the one out of 19 studies that examined behaviour in 1990. In the recent focal ischemia

Table 1: Study characteristics for recent $(2000$ - 2002) global and focal ischemia efficacy experiments

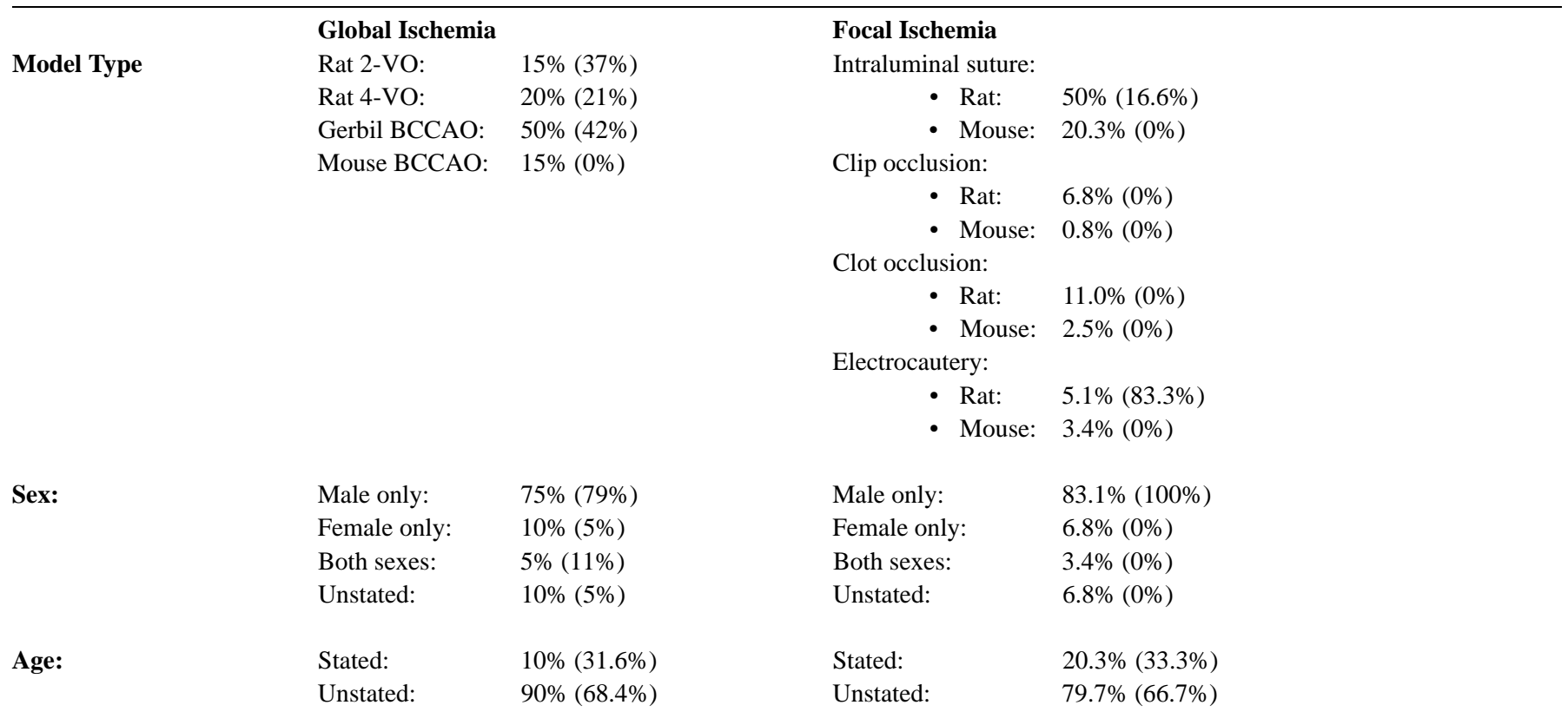

two-vessel occlusion plus systemic hypotension (2-VO); four-vessel occlusion (4-VO);

bilateral common carotid artery occlusion (BCCAO); middle cerebral artery occlusion (MCAO)

While many papers did not state the age, a weight range was commonly given or they stated "adult." Many of the ischemia studies that included females studied estrogen or related compound. No study examined sex differences in the efficacy of any other cytoprotectant. The data from 1990 are given in parenthesis within the Table. 


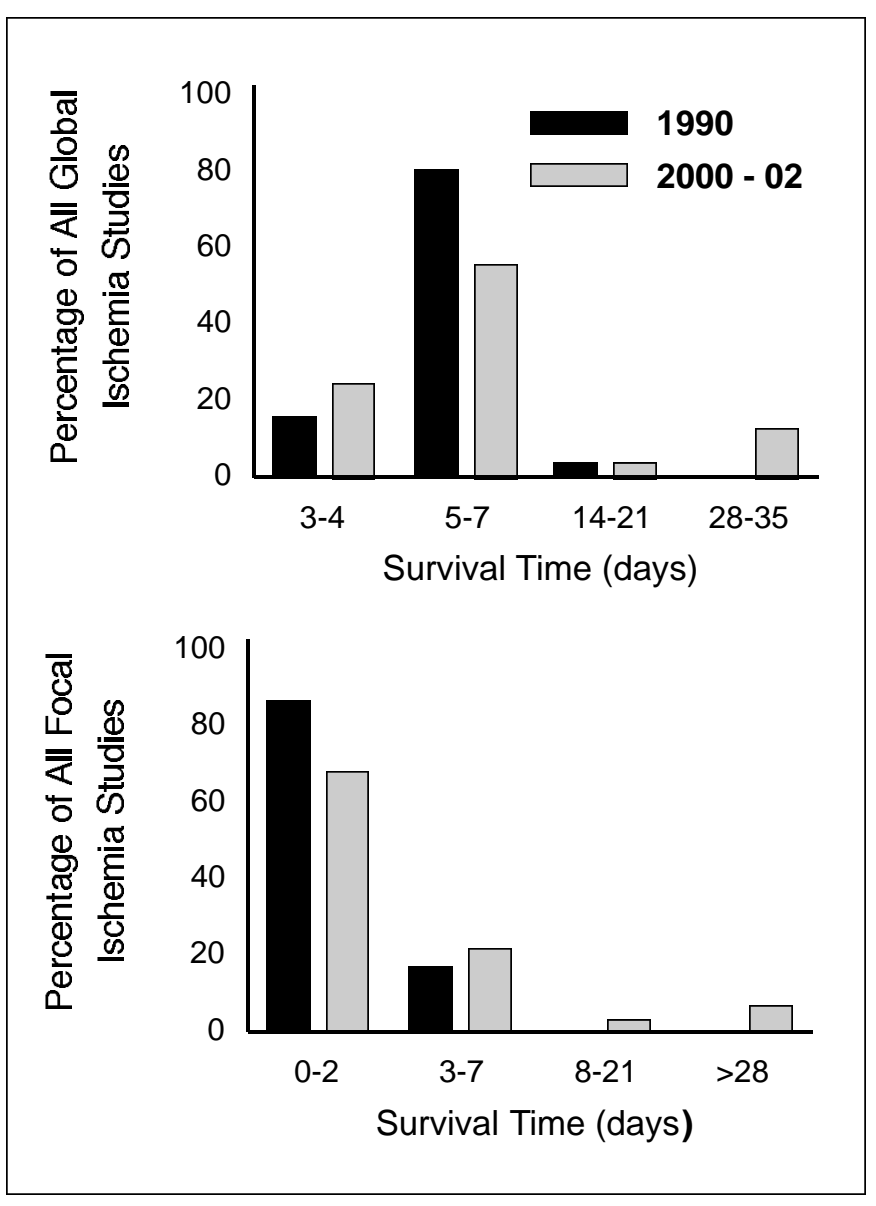

Figure 1: Percentage of 1990 and 2000 - 2002 studies categorized according to the longest survival time used and according to use of either a global (top) or focal (bottom) ischemia model. Of 20 global ischemia efficacy studies (2000 - 2002) only one was a negative finding at a seven-day survival time; thus that survival was sufficient. Another study found protection at a seven but not a 28-day survival time.

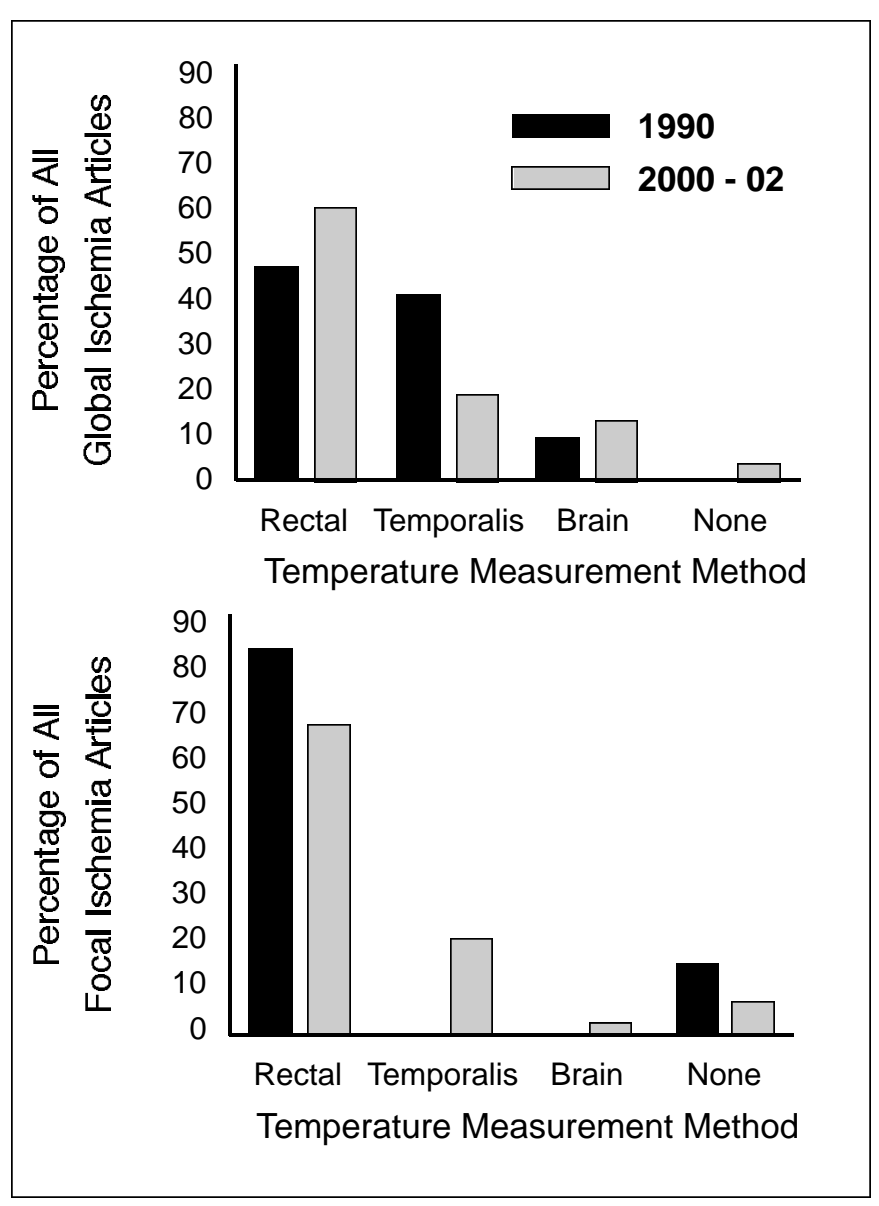

Figure 2: Intra-ischemic temperature measurement methodology for global and focal ischemia models categorized as: 1) rectal or core temperature, 2) tympanic or temporalis muscle temperature (with or without rectal/core measurements), 3) direct brain temperature measurement (with or without other measures) or 4) unstated/none for 1990 and 2000 - 2002 inclusive. studies, $55.1 \%$ did not assess functional outcome, $33.9 \%$ used some sort of NDS alone, and $11.0 \%$ used additional testing (e.g., skilled reaching) with or without a NDS. None of the 1990 studies used behavioural assessment as an endpoint.

The majority of global and focal ischemia studies used either rectal or core temperature measurements during ischemia without any other means of predicting brain temperature (Figure 2). Some studies utilized temporalis muscle (or skull) temperature. Very few studies directly measured brain temperature. Telemetry probes (core, brain, temporalis muscle) were rarely used in recent studies (15\% of global ischemia studies; $2.5 \%$ of focal ischemia studies), and not at all in the 1990 papers we surveyed.

Postsurgical temperature measurement after global ischemia, defined as any measurement beyond the end of anesthesia, which is likely $<10$ minutes following the end of occlusion, occurred in three out of 19 and six out of 20 studies published in 1990 and 2000 - 2002, respectively. The three 1990 studies sampled rectal temperature intermittently for up to 2,6 or $24 \mathrm{hr}$. Three of the 2000 - 2002 studies measured continually with telemetry probes for at least $24 \mathrm{hr}$. The other three studies sampled rectal temperature up to either one or two hours following ischemia. Several other studies stated that animals were placed in a room or a chamber with constant temperature for several hours after ischemia, but the animals' temperature was apparently not measured. The percentage of cytoprotection studies in focal ischemia that measured temperature following surgical anesthesia, even if once, was only $0 \%$ and $33.0 \%$ for 1990 and 2000 - 2002, respectively. Those 2000 - 2002 experiments that measured postsurgically were assessed for when they measured temperature and how often (see Methods, Figure 3). Only 3.4\% of all 2000 - 2002 focal studies used a telemetry probe (e.g., core temperature). Most studies typically used intermittent rectal probe measurements. Sometimes animals were placed in temperature-controlled rooms without measuring the animals' temperatures. 


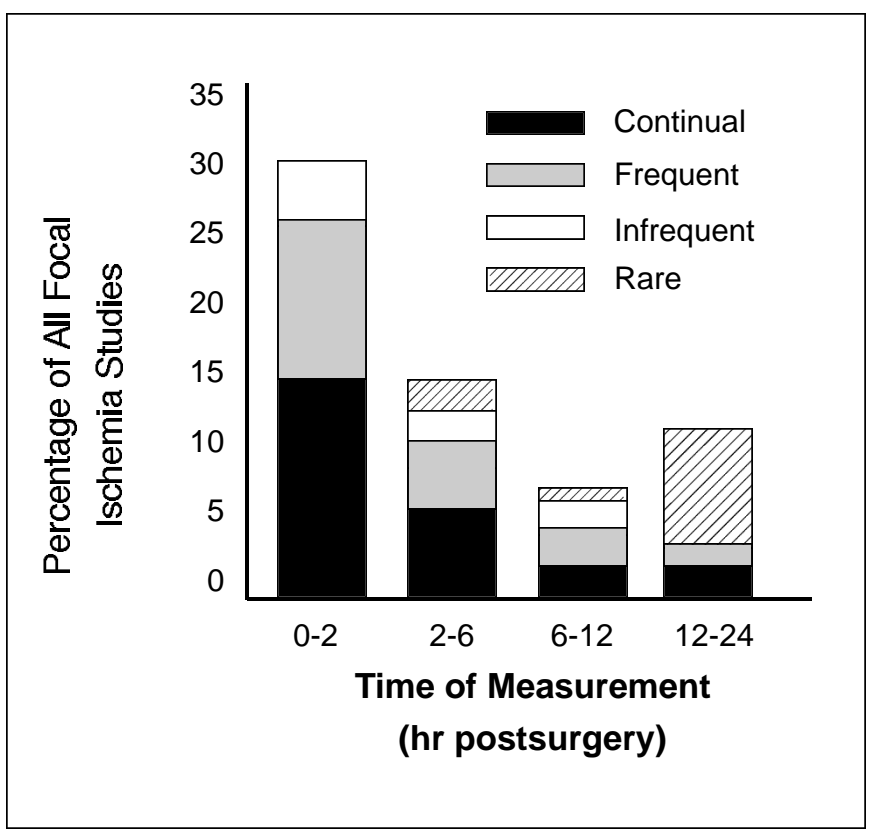

Figure 3: Percentage of focal ischemia cytoprotection studies (2000 2002) that measured temperature following surgery. None of the 1990 focal ischemia studies measured postoperative temperature. Data are broken down according to the time of the postoperative temperature measurement and by whether the sampling regimen was continual, frequent, infrequent or rare (see Methods). The reperfusion time was considered the "end of surgery" in those few studies that used prolonged anesthesia.

\section{Discussion}

Numerous "cytoprotectants", which were beneficial in rodent ischemia studies, failed clinical trials. As reviewed ${ }^{1-4}$ this inability to translate positive results from the bench to the bedside is due to incomplete experimental testing as well as limitations of clinical studies. Unfortunately, this survey of recent rodent ischemia studies demonstrates that most current experimental studies do not accurately represent clinical conditions of ischemia (e.g., aged animals) and many continue (cf. 1990 data) to have serious limitations that will likely contribute to further clinical failures.

Of greatest concern was the fact that $66 \%$ of focal and $80 \%$ of recent global ischemia cytoprotection studies used survival times of $\leq 48 \mathrm{hr}$ and seven days, respectively. These survival times, and even somewhat longer ones (e.g., two weeks), are not necessarily sufficient to allow injury to mature fully. ${ }^{8,10-14}$ This is shown, for instance, in one of the papers surveyed where flavopiridol reduced CA1 cell death at a seven but not a 28 day survival. ${ }^{14}$ Thus, the reduction in cell death observed in most experiments surveyed likely overestimates long-term benefit. The use of longer survival times (e.g., one month) is clearly required and usually easily achieved.

Only $45 \%$ of focal and $10 \%$ of global ischemia studies in 2000 - 2002 assessed behaviour. Thus, studies that did not assess behaviour may have overestimated benefit since not all reductions in cell death will translate into improved functional outcome. Conversely, behavioural improvements may occur without substantial reductions in cell death. Of those studies that assessed behaviour, most used only a NDS soon after injury (e.g., in first day). There are several potential problems with this approach. First, in some studies the animals were under the influence of the cytoprotectant at that time of behavioural testing. Second, the scales varied greatly (e.g., 2 - 10 point scales) and they were often not clearly described in the Methods, which makes it difficult to compare among studies. Third, a NDS, even the more comprehensive scales, may not necessarily predict long-term outcome. Indeed, deficits on these scales often resolve within a few weeks. ${ }^{16}$ Only a few studies used another functional test (e.g., skilled reaching) that reveals more persistent behavioural abnormalities. Regardless, recovery on either NDS or more sophisticated tests (e.g., staircase test) was never evaluated with respect to whether animals used compensatory strategies or whether they truly recovered (i.e., regained the original movement sequences in the test). ${ }^{17}$ The latter would be expected to better predict clinical findings.

Most recent studies (82\%) used male rodents. The inclusion of female animals is crucial, as approximately half of all ischemic insults occur in females. Only a very small number of the latest studies ( $1.5 \%$ overall) used aged animals. In order to efficiently and adequately evaluate potential cytoprotectants, studies demonstrating benefit in aged animals and both sexes are clearly required, at least at some point in the preclinical process. This does not appear to be happening.

Cerebral ischemic injury is critically dependent upon intraischemic temperature. ${ }^{22,23}$ Most studies assessed temperature during ischemia. Rectal temperature was most commonly used. However, while it roughly predicts brain temperature in conscious rodents $^{43}$ this is not the case during global ischemia. ${ }^{24-26}$ Accordingly, many of the global ischemia studies that used only rectal temperature measurements may be confounded by unknown variations in brain temperature. The relationship between brain and rectal temperature in focal ischemia is more complex and likely depends critically upon blood flow among other factors (e.g., craniotomy vs. intraluminal suture models, use of anesthesia, species).

Postischemic temperature can substantially modify focal ischemic brain damage. For example, delayed hypothermia reduces infarct $\operatorname{size}^{29-32}$ and delayed hyperthermia aggravates infarction. ${ }^{35-37}$ Only a minority of global and focal ischemia studies measured postsurgical temperature even though all of the ischemia models have been shown to affect postoperative temperature. ${ }^{12,28,32,34,44,45}$ Given these findings and the possibility of drug interactions, it is remarkable that most studies did not assess postsurgical temperature at all, including those using drugs known to affect temperature. Furthermore, of those that did, many only took rectal probe measurements for a short period following ischemia, or sampled temperature too infrequently (e.g., one sample at $24 \mathrm{hr}$ after middle cerebral artery occlusion) or not long enough following drug administration (e.g., $15 \mathrm{~min}$ ) to rule out temperature confounds. For instance, MK-801 can causes large fluctuations in temperature that oscillate between moderate hypothermia and normothermia. ${ }^{46}$ Such large temperature changes are easily missed with intermittent sampling. Furthermore, rectal temperature measurements can 
cause stress-induced fever, which occurs to differing levels in normal and ischemic animals. ${ }^{47}$ Thus, it is quite possible, and highly probable, that undetermined temperature alterations have confounded many cytoprotectant studies.

Several investigators placed animals in temperaturecontrolled chambers or rooms following ischemia, but surprisingly some did not then assess the animals' temperature. While this procedure would reduce the magnitude of hypothermia it would not prevent group differences nor prevent hyperthermia. Others claimed that the cytoprotective drug had been previously shown to have no temperature effect despite the fact that the temperature effects of a drug depend upon too many factors (e.g., dosing regimen, ischemia injury, species, sex, etc.) to justify this claim. We strongly recommend that: 1) the method and exact duration of temperature measurement be clearly stated, 2 ) investigators should not rely upon historical data with respect to temperature effects of a drug, 3) investigators should not rely solely upon temperature data from a limited subset of animals, and 4) investigators measure temperature with telemetry probes that allow for repeated and nonstressful data collection. The latter allows for temperature confounds to be clearly ruled out, and is also necessary for precise control of temperature, which then lessens variability in outcome. ${ }^{44}$

There are several limitations of this survey that must be considered. First, we did not examine articles published in other journals. Given the high status (e.g., impact factor) of the journals surveyed, we do not expect any different conclusions if other journals had been included in our survey and did not notice any differences among the journals that we did survey. Second, we cannot exclude the possibility that each treatment has been or would be investigated in a more thorough manner prior to clinical investigation. Our results simply indicate that this is not common. Third, we did not identify those differences between positive and negative findings for each drug that might account for the latter (e.g., absence vs. presence of temperature control). There were simply too few negative studies to do this. Fourth, we did not survey many other important factors that affect ischemic injury such as cerebral blood flow, plasma or CSF drug levels, glucose levels, etc. These must also be carefully considered in evaluating cytoprotection literature, but were beyond the scope of this survey. Finally, it could be argued that insufficient time has elapsed since the identification of these limitations (e.g., brief survival times) for experimental design to improve in the studies we examined. For instance, the STAIR report ${ }^{3}$ was published in 1999 and thus investigators that adhered to these recommendations could only start publishing improved studies in late 2000 or 2001 . We did not notice any trends within the 2000 - 2002 years and thus we grouped the data. Furthermore, given that the STAIR report was based upon many previous experimental findings and reviews, some published in the 1980s and others in the early 1990s, we feel that there has been more than sufficient time to allow investigators to improve their study design. It appears that neither those original reports nor STAIR (and perhaps this survey) has had a sufficient impact.

Experimental cytoprotectants have not translated well from the bench to the bedside. This translation failure is due to limitations and design flaws in both preclinical and clinical studies. While these limitations are widely recognized, the present survey, which characterized only a few of them, shows that many investigators have not taken these concerns seriously enough to better design rodent studies to avoid major physiological confounds and to better represent clinical conditions of cerebral ischemia. Notably, many studies failed to use: female or aged animals, behavioural assessment, longer survival times, or proper temperature control. Perhaps this is due to the increased costs and time associated with the use of longer survival times, behavioural assessments and physiological controls. As well, investigators feel the urge to publish findings quickly or may assume that other investigations will eventually examine these issues (e.g., whether protection is permanent).

Without significant changes to the design of rodent studies we expect further clinical failures. Thus, we strongly recommend that investigators more seriously consider these issues and that journal editors and reviewers at least insist upon better disclosure and discussion of these methodological concerns. Finally, while there are no perfect experimental (or clinical) studies, we expect that every attempt to account for the major limitations and confounding factors discussed herein will result in better predictive accuracy and eventual clinical success.

\section{ACKNOWLEDGEMENTS}

The authors acknowledge research support by the Alberta Heritage Foundation for Medical Research (AHFMR). The authors thank Maria Sung, an AHFMR HYRS student, for help on article collection. Dr. Colbourne is the recipient of an AHFMR scholar award. Crystal MacLellan is the recipient of a Natural Sciences and Engineering Research Council of Canada graduate scholarship.

\section{REFERENCES}

1. Gladstone DJ, Black SE, Hakim AM. Toward wisdom from failure: lessons from neuroprotective stroke trials and new therapeutic directions. Stroke 2002;33:2123-2136.

2. Corbett D, Nurse S. The problem of assessing effective neuroprotection in experimental cerebral ischemia. Prog Neurobiol 1998;54:531-548.

3. Stroke Therapy Academic Industry Roundtable (STAIR). Recommendations for standards regarding preclinical neuroprotective and restorative drug development. Stroke 1999;30:2752-2758.

4. DeGraba TJ, Pettigrew LC. Why do neuroprotective drugs work in animals but not humans? Neurol Clin 2000;18:475-493.

5. Garcia JH, Yoshida Y, Chen H, et al. Progression from ischemic injury to infarct following middle cerebral artery occlusion in the rat. Am J Physiol 1993;142:623-635.

6. Kirino T. Delayed neuronal death in the gerbil hippocampus following ischemia. Brain Res 1982;239:57-69.

7. Pulsinelli WA, Brierley JB, Plum F. Temporal profile of neuronal damage in a model of transient forebrain ischemia. Ann Neurol 1982;11:491-498.

8. Colbourne F, Li H, Buchan AM. Continuing postischemic neuronal death in CA1 : influence of ischemia duration and cytoprotective doses of NBQX and SNX-111 in rats. Stroke 1999;30:662-668.

9. Garcia JH, Liu K-F, Ye Z-R, Gutierrez JA. Incomplete infarct and delayed neuronal death after transient middle cerebral artery occlusion in rats. Stroke 1997;28:2303-2310.

10. Du C, Hu R, Csernansky CA, Hsu CY, Choi DW. Very delayed infarction after mild focal cerebral ischemia: a role for apoptosis? J Cereb Blood Flow Metab 1996;16:195-201.

11. Dietrich WD, Busto R, Alonso O, Globus MY-T, Ginsberg MD. Intra-ischemic but not postischemic brain hypothermia protects chronically following global forebrain ischemia in rats. J Cereb Blood Flow Metab 1993;13:541-549.

12. Colbourne F, Corbett D. Delayed postischemic hypothermia: a six month survival study using behavioural and histological assessments of neuroprotection. J Neurosci 1995;15:7250-7260. 
13. Valtysson J, Hillered L, Andine P, Hagberg H, Persson L. Neuropathological endpoints in experimental stroke pharmacotherapy: the importance of both early and late evaluation. Acta Neurochir (Wien) 1994;129:58-63.

14. Wang F, Corbett D, Osuga H, et al. Inhibition of cyclin-dependent kinases improves CA1 neuronal survival and behavioural performance after global ischemia in the rat. J Cereb Blood Flow Metab 2002;22:171-182.

15. Wahl F, Allix M, Plotkine M, Boulu RG. Neurological and behavioural outcomes of focal cerebral ischemia in rats. Stroke 1992;23:267-272.

16. Cregan EF, Peeling J, Corbett D, et al. [(s)-alpha-phenyl-2-pyridineethanamine dihyrdochloride], a low affinity uncompetitive $\mathrm{N}$ methly-D-aspartic acid antagonist, is effective in rodent models of global and focal ischemia. J Pharm Exp Therap 1997;283:1412-1424.

17. Whishaw IQ. Loss of the innate cortical engram for action patterns used in skilled reaching and the development of behavioural compensation following motor cortex lesions in the rat. Neuropharmacology 2000;39:788-805.

18. Duverger D, MacKenzie ET. The quantification of cerebral infarction following focal ischemia in the rat: influence of strain, arterial pressure, blood glucose concentration, and age. J Cereb Blood Flow Metab 1988;8:449-461.

19. Futrell N, Garcia J, Peterson E. Embolic stroke in aged rats. Stroke 1991;22:1582-1591.

20. Sutherland GR, Dix GA, Auer RN. Effect of age in rodent models of focal and forebrain ischemia. Stroke 1996;27:1663-1667.

21. Roof RL, Hall ED. Gender differences in acute CNS trauma and stroke: neuroprotective effects of estrogen and progesterone. J Neurotrauma 2000;17:367-388.

22. Dietrich WD, Busto R, Globus MYT, Ginsberg MD. Brain damage and temperature: cellular and molecular mechanisms. Adv Neurol 1996;71:177-194.

23. Colbourne F, Sutherland G, Corbett D. Postischemic hypothermia: a critical appraisal with implications for clinical treatment. Mol Neurobiol 1997;14:171-201.

24. Busto R, Dietrich W, Globus M-T, et al. Small differences in intraischemic brain temperature critically determine the extent of ischemic neuronal injury. J Cereb Blood Flow Metab 1987;7:729738.

25. Colbourne F, Nurse SM, Corbett D. Temperature changes associated with forebrain ischemia in the gerbil. Brain Res 1993;602:264267.

26. Minamisawa $H$, Mellergard $P$, Smith ML, et al. Preservation of brain temperature during ischemia in rats. Stroke 1990;21:758-764.

27. Baena RC, Busto R, Dietrich WD, Globus MY, Ginsberg MD. Hyperthermia delayed by 24 hours aggravates neuronal damage in rat hippocampus following global ischemia. Neurology 1997; 48:768-773.

28. Coimbra C, Boris-Möller F, Drake M, Wieloch T. Diminished neuronal damage in the rat brain by late treatment with the antipyretic drug dipyrone or cooling following cerebral ischemia. Acta Neuropathol 1996;92:447-453.

29. Kim Y, Busto R, Dietrich WD, et al. Delayed postischemic hyperthermia in awake rats worsens the histopathological outcome of transient focal cerebral ischemia. Stroke 1996;27:2274-2281.

30. Memezawa H, Zhao Q, Smith ML, Siesjo BK. Hyperthermia nullifies the ameliorating effect of dizocilpine maleate (MK-801) in focal cerebral ischemia. Brain Res 1995;670:48-52.

31. Reglodi D, Somogyvari-Vigh A, Maderdrut JL, Vigh S, Arimura A. Postischemic spontaneous hyperthermia and its effects in middle cerebral artery occlusion in the rat. Exp Neurol 2000;163:399407.

32. Zhao Q, Memezawa H, Smith ML, Siesjo BK. Hyperthermia complicates middle cerebral artery occlusion induced by an intraluminal filament. Brain Res 1994;649:253-259.

33. Colbourne F, Corbett D. Delayed and prolonged postischemic hypothermia is neuroprotective in the gerbil. Brain Res 1994;654:265-267.

34. Hickey RW, Ferimer H, Alexander HL, et al. Delayed, spontaneous hypothermia reduces neuronal damage after asphyxial cardiac arrest in rats. Crit Care Med 2000;28:3511-3516.

35. Colbourne F, Corbett D, Zhao Z, Yang J, Buchan AM. Prolonged postischemic hypothermia: a long-term outcome study in the rat middle cerebral artery occlusion model. J Cereb Blood Flow Metab 2000;20:1702-1708.

36. Corbett D, Hamilton M, Colbourne F. Persistent neuroprotection with prolonged postischemic hypothermia in adult rats subjected to transient middle cerebral artery occlusion. Exp Neurology 2000;163:200-206.

37. Maier CM, Sun GH, Kunis D, Yenari MA, Steinberg GK. Delayed induction and long-term effects of mild hypothermia in a focal model of transient cerebral ischemia: neurological outcome and infarct size. J Neurosurg 2001;94:90-96.

38. Coimbra C, Wieloch T. Moderate hypothermia mitigates neuronal damage in the rat brain when initiated several hours following transient cerebral ischemia. Acta Neuropathol 1994;87:325-331.

39. Colbourne F, Sutherland GR, Auer RN. Electron microscopic evidence against apoptosis as the mechanism of neuronal death in global ischemia. J Neurosci 1999;19:4200-4210.

40. Corbett D, Evans S, Thomas C, Wang D, Jonas R. MK-801 reduces cerebral ischemic injury by inducing hypothermia. Brain Res 1990;514:300-304.

41. Buchan AM, Pulsinelli W. Hypothermia but not the N-methyl-Daspartate antagonist, MK-801, attenuates neuronal damage in gerbils subjected to transient global ischemia. J Neurosci 1990;10:311-316.

42. Nurse S, Corbett D. Neuroprotection after several days of mild, drug-induced hypothermia. J Cereb Blood Flow Metab 1996; 16:474-480.

43. DeBow S, Colbourne F. Brain temperature measurement in awake and freely moving rodents. Methods 2003;30:167-171.

44. Colbourne F, Li H, Buchan AM. Indefatigable CA1 sector neuroprotection with mild hypothermia induced 6 hours after severe forebrain ischemia in rats. J Cereb Blood Flow Metab 1999; 19:742-749.

45. Corbett D, McKay K, Wight V, Granter-Button S. Effects of different postischemic temperature regulation regimens on focal ischemic outcome in the mouse. Soc Neurosci Abst 2002;28:abst. \# 491.411 .

46. Colbourne F, Sutherland GR, Auer RN. An automated system for regulating brain temperature in awake and freely moving rodents. J Neurosci Meth 1996;67:185-190.

47. Clark DL, DeBow SB, Iseke MD, Colbourne F. Stress induced fever after postischemic rectal temperature measurements in the gerbil. Can J Physiol Pharmacol 2003:in press. 